\title{
Identity and Perception of Risk for Entrepreneurs: Lessons from an Industrially Less Developed State in India
}

\author{
By Debdatta Saha*
}

\begin{abstract}
Identity matters for entrepreneurship in business environments marked by financial market imperfections. In the absence of formal finance, much of the economics literature on entrepreneurship focuses on the interplay of moral hazard and limited liability in explaining outcomes. However, this formulation of the problem bypasses a discussion of how entrepreneurial identity informs her perception of business prospects. While a recent branch of the literature has introduced the importance of social networks in enabling access to finance in developing countries, it does not address the issues an entrepreneur faces in developing an "identity" by belonging to a particular region or place. This paper addresses the aspect of location-based counterfactual thinking (CFT) in identity formation (which is created naturally by being a native member of a region) and its impact on the risk perception of entrepreneurs in the context of an industrially backward region. While the empirical results of the paper are drawn from a primary survey in the state of Bihar, India conducted in 2016 through snowball sampling for food processing industries, the results generalize to any context of entrepreneurial identity in the background of a low industrial base. Drawing insights from enterprise ecology, we find that (i) counterfactual thinking matters for risk perception and that (ii) both these variables change over the lifetime of entrepreneurship. We find that as the experience of the entrepreneur increases and she/he accesses more business networks/ associations, perception of risk is lowered. Alongside, the negative affect in counterfactual thinking (linked to a location-based identity) changes to positive affect with experience and exposure to business networks. The policy lesson from this exercise is that industrial policy initiatives must go beyond pecuniary incentives and pro-actively engaging in supporting entrepreneurial learning to strengthen investments and industrial outcomes in states like Bihar.
\end{abstract}

Keywords: counterfactual thinking, Entrepreneurial identity, entrepreneurial risk perception, industrial policy

\section{Introduction}

A large body of literature exists on entrepreneurship, starting with seminal work by Schumpeter (1934) continuing in the neo-classical mainstream with studies by Kihlstrom and Laffont (1979) and Baumol (1993), in the discipline of economics. Other disciplines, such as organizational ecology (for instance, Gartner 1985, Gartner et. al. 1994) and social psychology (such as McClelland 1965, McGrath and MacMillan 2000) have provided important inputs regarding entrepreneurial motivation and behavior. Recent advances in entrepreneurial research has incorporated the important question of entrepreneurial identity; for

\footnotetext{
*Assistant Professor, South Asian University, New Delhi, India.
} 
instance, Murnieks and Mosakowski (2007) which assumes an important dimension in industrial spaces with low business concentration and therefore, sparse business networks. Defining entrepreneurial identity as a set of beliefs "commonly" held by the population and internalized by the cognitive processes of the entrepreneur, the literature points out its relation to roles that are attached to this identity. In a sense, these roles assign meaning to the term entrepreneur. A comprehensive view of these roles comes from Shane and Venkataraman (2000), who interpret an entrepreneur as a person engaged in the discovery, examination and exploitation of opportunities.

We contend that roles are not sufficient in themselves to provide a meaningful interpretation of entrepreneurial identity. We argue for the incorporation of the spatial context in the definition of who is an entrepreneur. The reason for this extension of dimension of definition is motivated by our survey of entrepreneurial risk perception in the Indian state of Bihar, which has had a history of law and order problems resulting in flight of capital and a low industrial base at present. Despite Gartner's (1989) commentary that research in entrepreneurial identity is likely to yield less dividends than a direct quest of behavior, it is our contention (corroborated by Murnieks \& Mosakowski (2007)) that embedding the question of motivation and behavior in the particularities of locational understanding of entrepreneurial roles and therefore identity (ies) is a much more meaningful investigation into entrepreneurial motivation and behavioral outcomes.

The central research question we investigate in this paper is: how does the locational context influence entrepreneurial behavior reflected in her/his perceptions of risk? Our hypothesis is that locational conditions, particularly in extreme conditions such as the one we describe give shape to entrepreneurial identities through the cognitive process of counterfactual thinking (CFT) in the form of regrets about being captive to the region, particularly when business outcomes are bad. These counterfactual thoughts get reflected in risk perceptions. We find that regrets about being native to a region like Bihar is markedly present in novice entrepreneurs, whereas this counterfactual thinking reverses (entrepreneurs express a desire to do business in Bihar due to its input advantages in the industry of food processing) for experienced entrepreneurs ${ }^{1}$ who have multiple memberships in business associations. These points to the influence of business networks and their mitigating influence on entrepreneurial cognition.

Our contention is that the kind of location-based identity that we discuss arises due to the history of Bihar, which has experienced severe law and order problems. From the 1980s to 2006, the state experienced what is called "jungle raj" or the law of the jungle, with a cottage industry of kidnappings and threats to functional entrepreneurs in the state (Chakrabarti 2013, Mukherji and Mukherji 2012). We have interviewed the proprietor of a restaurant in a very busy part of the capital city, Patna, who was kidnapped twice and had to shift his family out of the state for survival. The easy kidnapping targets (middle-sized enterprises) exited the state leaving behind the very small (not lucrative targets for the kidnappers) or a few very large industrialists (who could buy their protection) resulting in an

\footnotetext{
${ }^{1}$ Prior experience comes mostly as traders in the business supply chain.
} 
industrial structure that is referred to in the academic literature as the "missing middle" problem, which we illustrate in our paper.

The lessons from Bihar serve as a good example for similarly placed states, particularly in terms of the role of industrial policy. Our paper provides a test for whether entrepreneurial risk perceptions respond to governmental actions such as the provision of subsidies, which is not present in our data. As perceptions feed into industry outcomes through the channel of entrepreneurial investment behavior with a time lag, this missing middle problem is likely to be strengthened over time unless entrepreneurial expectations change, so that expansion in capacity is made by small firms along with simultaneous entry of mid-sized firms into the industry. This can only happen with infrastructure encouraging better flows of information (business networks/ business associations) and with entrepreneurs with prior experience (particularly in trading or some other part of the supply chain) entering business. While these results are drawn from a primary survey in one particular industry (food processing) in Bihar, we believe that these results will be stronger for other industries, where Bihar does not have a clear input advantage. Unless entrepreneurial risk perceptions are reflective of positive counterfactual thinking (individuals opine that they would do business in the state even if they were not native to the state), future investments and capacity expansion is unlikely to follow even with government provision of pecuniary support.

The paper is structured as follows: we first present a brief survey of the literature on identity and cognition in entrepreneurship, while clearly underlining the contribution of the paper to the extant literature. We, then, delineate our empirical methodology and the development of empirically testable hypotheses. We follow up with descriptive statistics of the sample along with results regarding the hypotheses and a test for the representativeness of the sample. We provide some policy recommendations prior to the conclusion of the paper.

\section{Literature Review}

Most of the literature on entrepreneurship studies the discipline along the lines of individual entrepreneurial traits (innate ability) or through cognitive approaches to entrepreneurial decision-making (Sánchez et al. 2011). Another branch of entrepreneurship, which is relatively neglected and has limited number of papers and application, is entrepreneurial identity (Murnieks and Mosakowski 2007). These branches of the literature are somewhat independent of each other. The traits-based approach predefines the identity and associated roles of an entrepreneur and searches for individual traits that result in successful entrepreneurship. Despite its success in predicting outcomes, this approach sets rigid boundaries to who is or who is not an entrepreneur by placing central status to innate traits possessed by individuals. This does not address the process of how sometimes non-entrepreneurs or forced entrepreneurs (without innate ability) which is what we are interested in. Is it possible for a regional government to foster entrepreneurs in a region with very little entrepreneurship and low industrial base? 
If we explore the identity-based exploration of entrepreneurship, we find its exclusive engagement with the relationship between who an entrepreneur believes she/he is and her/his roles/actions to be performed in the conduct of business. Now, what forms the identity standard? A structural identity theory (Burke and Stets 2009) point out that identity is what is internalized by the entrepreneur as his/her role. In many situations, this internalized identity is a self-concept (not influenced by external influences), so that attitudes such as perception of risk and resultant investment behavior is left to the agent himself/herself (for instance, Gimeno et. al (1997) point out that entrepreneurs are motivated from within). There is no direct superimposition from social norms or network standards regarding this identity. The entrepreneur tries to live up to his or her own selfcreated standard.

Next comes to the issue of the constituents of identity: for instance, what is the content of identity? Is it unidimensional or multi-dimensional? Regarding content, there are multiple contenders in the literature. Cast (2004) claims "an identity is a set of meanings that represent the self in a social role, defining who one is in that status" (p. 57). Stryker and Serpe (2000) note that these are "reflexively applied cognitions that answer the question 'Who am I?" Regarding the content of entrepreneurial identity, Murnieks and Mosakowski (2007) note that there is relatively paucity of academic investigation. We contend that entrepreneurs develop their identities in two ways: one, by absorbing socially-held behavior expectations attached to positions. By definition, these are external to the individual and are assimilated into the entrepreneur's notion of self through a process of absorption (Gecas 1982). An example is the exploration of entrepreneurial identity resulting from an individual's socialization in the context of school peers shaping entrepreneurial intentions (Falck et al. (2012)). Second is a set of ideas held internally by the entrepreneur? For instance, Baum et al. (2001), Baum and Locke (2004), Chen et al. (2009), Cardon et al. (2009) as well as Murnieks et al. (2012) identify passion as a driving force in entrepreneurship, a factor that is innate to the entrepreneur and potentially empowers her/him to fight external resistance and problems in doing business. These identities, whether absorbed in from the external environment or part of the internal belief set of the entrepreneur, are multidimensional entities and display stability as well as individual peculiarities, due to differential absorption of concepts or variation in internal notions of identity (McCall and Simmons 1978).

The obvious question that arises is about the relationship of entrepreneurial identity with the third approach to entrepreneurship that is cognitive in nature. Irrational factors such as heuristics and reasoning fallacies such as planning errors (Baron and Markman 1999), overconfidence (Russo and Schoemaker 1992, Kahneman and Tversky 1973); over-optimism (Dawson and Henley 2013)) and counterfactual thinking (Hmieleski and Corbett 2008, Markman et al. 2005, Zhao et al. 2005) are a part of this branch of the literature. Its pro-active concern about the actual decision-making process rather than innate traits that lead to successful entrepreneurship sets this branch of the literature apart (Sánchez et al. 2011). And yet, very few papers have clearly pointed out the link between the identity based and the cognitive approach to entrepreneurship, which is critical for the context 
that we are interested in whereby ordinary individuals become active entrepreneurs in difficult business environments.

One exception in the entrepreneurship identity literature is Burke (2004). By likening the process of entrepreneurship to control systems, he forcefully links identity with counterfactual thinking (CFT). He defines the process of entrepreneurial identity as: "A cyclical process occurs when an individual takes some action, views that action, evaluates the results in comparison with the standards embodied within an identity, and then incorporates this new information to modify his or her behavior to improve the expected results." Behavior is continually altered until feedback matches the identity standard (Burke 1991a). A perfect match results in self-verification leading to a variety of emotions (ranging from satisfaction to elation) depending upon the context. When the match fails to take place, self-verification fails leading to cognitive dissonance and varying levels of distress (Burke 1991b). The in-built identity(ies) then motivate behavior modification until feedback matches identity standards, so that the individual can avoid distress associated with the lack of self-verification and enjoy the positive outcomes where self-verification is achieved (Burke 1991b).

However, an important aspect of the identity creation process is that it is understood by its relation to other identities, which it does not encompass (Burke 1980). As Murnieks and Mosakowski (2007) point out, the identity of "wife" gets defined associationally with that of "husband". Hence, an entrepreneurial identity rests heavily on how the person defining it views non-entrepreneurial identities. This has special importance in the context of such identities in geographical areas with low industrial bases, where the firm finds its operations limited by local market size, has limited exposure to external markets and has very sparse business networks to interact with. Entrepreneurship here gets tightly associated with the regional context within which the business is confined (here we assume that there are not many export and trade linkages with rest of the world, which is the case for the case we study). Essentially, in the case of Bihar, and entrepreneur considers that he is not only engaged in doing business, but also that she/he is "doing business in Bihar". This link of regional identity and CFT has not been pointed out by either the cognitive or the identity aspects of the entrepreneurship literature.

How does this regional/local contextualization matter in defining identity? Our paper shows that this aspect of local identity shows up in a particular kind of cognitive CFT, particularly in regions with poor industrial infrastructure and outcomes. To build this context, we borrow the definition of entrepreneurial identity from Haynie et al. (2009), who define entrepreneurship as a process of envisioning the future. This process necessarily entails CFT of the kind "what might have been had different actions been undertaken or had circumstances been different".

However, CFT is a broad collection of cognitions that an entrepreneur engages in situations of stress, as pointed out earlier (Baron 2000, Markman et al. 2005). CFT is in a sense a display of cognitive dissonance and allows the entrepreneur to explain away unpalatable outcomes and situations to themselves in order to move ahead (Wadeson 2006). There are many kinds of CFT and it is therefore unsurprising that the empirical evidence about entrepreneurial CFT is not 
conclusive. While some researchers (Baron 2008, 2000) show that entrepreneurs do not engage in as much CFT as non-entrepreneurs, Gaglio and Katz (2001) and Gaglio (2004) in fact show that entrepreneurs have very complex thinking processes and engage in significant CFT. It is at this point in the literature that we start working by picking up a very precisely defined type of CFT, which is linked to an entrepreneur's regional identity and show its effect on behavior which we again define narrowly as entrepreneurial risk perception, which papers such as Sitkin and Pablo (1992) and Sitkin and Weingart (1995) show are crucial in risktaking behavior of entrepreneurs.

\section{Contribution to the Literature}

Our contribution to the literature on entrepreneurship is two-fold. First, we provide a linkage between the identity and cognitive approaches to entrepreneurship by explicitly demonstrating the existence of a locational-identity based counterfactual thinking (CFT) that entrepreneurs engage in. CFT collects all varieties of coping mechanisms that are a part of the cognitive process of entrepreneurial decision-making. We model a particular category of CFT that derives its expression from the regional identity of the entrepreneur in the form of "had I not belonged to this region, I would not have done business here" thus relieving some of the cognitive distress due to non-performance. Whereas the identity literature has exclusively focused on the question of who the entrepreneur thinks she/he is in relation to her/his roles, we extend the identity issue into the cognitive process as reflected through CFT.

Second, the literature on CFT presents ambiguous results, with one branch clearly pointing to lack of CFT among entrepreneurs (Baron 2008, 2000) relative to non-entrepreneurs and another pointing to the presence of complicated CFT among entrepreneurs (for instance, Gaglio and Katz (2001)). We resolve this paradox partially by pointing out that rather than a quantitative absence or presence of CFT, our data reveals that the quality of this kind of cognition changes over the life-cycle of entrepreneurs. We find relatively novice entrepreneurs answer the question "would you have done business in Bihar had you not been native to the state" with a strong negative answer, experienced entrepreneurs in fact respond with a positive response (they would do business in the state of Bihar even if they were not native to the state). That experience matures an entrepreneur and changes the nature of cognition of the entrepreneur is also captured through a lower perception of risk for experienced entrepreneurs. Locational-identity based CFT is positively correlated with the cognitive perception of risk in our data. Further, we point out the channel which has the potential to mitigate the negative affect related to uncertain business outcomes. It is not policy variables such as government subsidy or business specific factors such as line of business, land size, access to institutional finance or inherited factors such as father's profession. We find membership in business associations, which are symbolic of the ties to business networks (Munshi 2010) is positively correlated with risk perceptions and hence CFT. Our argument runs along the following lines: Given that industrial outcomes have been stymied for a long period of time and that many businesses 
have not been able to expand in Bihar, a novice expresses her/his frustration of low business outcomes by ascribing the blame to being tied to the immediate context of Bihar rather than personal non-performance. As an entrepreneur gains experience despite being constrained to operate in the same region with low industrial achievements, his CFT changes from negative to positive and risk perception goes down. This is exhibited by the behavior of becoming members of more business associations. Potentially, entrepreneurial identity starts out as a selfconcept for a novice and over time assumes an identity mitigated by social norms and expectations, such that a non-entrepreneur (with negative locational-identity based CFT and risk perception) becomes an entrepreneur with experience with access to many business networks (with positive locational identity-based CFT and risk perception). We find Podoynitsyna et al. (2012) have explored the same issue from the dimension of mixed emotions in cognitive appraisal (we explore this through CFT). Their research also concludes that negative affect emotions change to positive ones along with changing risk perception as an entrepreneur gains experience. We surmise that it is incorrect to conclude either that entrepreneurs systematically disengage with CFT or otherwise. This cognitive process varies over the life-cycle of entrepreneurship, leaving clear implications for industrial policy that we discuss later in the paper.

\section{Methodology}

\section{Research Design}

We derive our estimates of CFT and risk perception through an empirical exercise using a primary survey among formal registered units (partnerships as well as limited liability companies for a total of 76 units) in Bihar in 2016-17 as part of an IGC-funded project "Study of the Food Processing Sector in Bihar". There is no published literature attempting this exercise for Bihar and there are many difficulties in contacting individual entrepreneurs through surveys (for instance Munshi (2010) details the difficulties of surveying entrepreneurs in the diamond trading and polishing industry).

We selected the food processing industries for conducting our survey, as Bihar has a natural input advantage in terms of agricultural raw materials ${ }^{2}$. Our choice of industry was corroborated in the survey, where entrepreneurs uniformly identified the input advantage of Bihar for food processing. Our sampling method is based on snowball sampling, as discussed in Noy (2008) and Newman (2018). This sampling technique is non-randomized and appropriate when the population is not known with certainty (for example, for hidden samples and networks). It is impossible to note at a point in time the total number of functional units unless the scale of the survey is very large, such as the ASI (Annual Survey of Industries). Given continuous entry and exit, exact data on the population of functional units is a rough estimate. The primary reason is that there is no legal restriction on an

${ }^{2}$ Successive Economic Surveys of the State of Bihar reveal the comparative sectoral advantage of food processing due to abundance of agricultural raw material available in the state. 
exiting firm to inform any authority that it is leaving business in any state in India. Lack of an industrial exit policy has exacerbated this problem. This problem apart, we found in our initial interactions with one of the prominent business association in the state (Bihar Industries Association (BIA)) that no individual entrepreneur would be forthcoming in their interviews unless given a proper reference for the surveyor, similar to the problems mentioned in Munshi (2010). While the diamond industry is by nature secretive, we presume it is the problematic history of the state in terms of law and order as discussed earlier that leads to reluctance on the part of the entrepreneur to reveal attitudes and business practices unless certified through proper agency.

With permission of the state government of Bihar, the Program Management Agencies (PMAs) ${ }^{3}$ and the BIA, we snowballed our sample from an initial source (with the BIA) and increased our sample size through referrals to friends and associates, ensuring a decent sample size across various sub-sectors of food processing. Our method also helped us identify some recently exited enterprises to include in our sample thus ensuring heterogeneity in units' operational status. The disadvantage, of course, is that it would be difficult to gauge population estimates from our sample. However, given that we have ensured the Fisherian principle ${ }^{4}$ of heterogeneity in samples, we believe that our sample estimates are close to the population estimates. In fact, we show that the missing middle size that is present in our sample is present in the population as well, which gives us confidence that our sample is representative of the population.

We conducted a mixture of telephonic and face-to-face interviews of entrepreneurs mostly from several districts in Bihar (such as Muzaffarpur, Patna, Gaya, Nalanda and Hajipur etc.). Two of the units surveyed resulted in managerial interviews and not that of the original entrepreneurs and hence were not included in the final sample for understanding perception of risk.

Our interest was to study the indigenous firms of Bihar, our strategy was to interview firms with production facilities in the state and not simply marketing their products, Given the large domestic consumption market, initial discussion with the business associations indicated that this risk is not as large as the risk of starting a business for established units. Of course, many small units have also indicated that marketing their product is a challenge in the local market. As we want to correlate the total risk of doing business with incentive policies for manufacturing, we have selected only those units which are engaged not only in marketing but also have production facilities within the state. Another related caveat is that the food processing industry has a long supply chain that extends from production to services. We have ignored the latter set of enterprises (such as restaurants serving processed food) from our sample, as risks involved in the physical production supply chain is very different from those in services (for instance, the World Bank Enterprise Survey uses different survey instruments to

\footnotetext{
${ }^{3}$ These agencies have been instituted by the state government for professional management of investment projects, particularly for helping the entrepreneur arrange necessary documentation and other proof for application for subsidies from the government.

${ }^{4}$ Fisher RA (1939) Student. Annals of Eugenics 9(1): 1-9.
} 
sample enterprises across different countries mentioning this issue of differential business structures in services and manufacturing).

\section{Defining Risk Perception and CFT in Entrepreneurial Identity}

As investment behavior and industrial outcomes are driven by perception of risk, rather than objectively measured risk, we focus on the variable of perceived risk. As mentioned earlier, we define the perception of risk in doing business as combination of production, marketing and security of property challenges that adversely affect profits. We do not segregate between different types of business risk, rather the total risk in operations (as a combination of production, marketing and protection of investment). We measure risk perception through two instruments:

(i) as a single variable that adversely affects profits of the enterprise: we measure this in two ways: one, as a direct scale measure of risk perception and second as a categorical variable with two categories (low risk and high risk). The first is a scale measure of perception of total risk for an entrepreneur. It is measured on a scale of zero to five, with zero reflecting very high-risk perception and 5 reflecting minimal risk perception. The categories 1 and 2 reflect high risk perception (value less than or equal to the average of 2.5) and low risk perception (value greater than 2.5) respectively. The cut-off of 2.5 is based on the mean value from $\mathrm{N}=72$ valid responses for this question. We refer to this categorized measure as the "risk code".

(ii)through a location-specific counterfactual: as a Bihar-specific issue that would not be present, had the entrepreneur been operating in another state. We asked the entrepreneur whether he/she would do business in Bihar had he/she not originated from Bihar and was an outsider. This second measure is intended to understand how much of a pure input advantage in food processing that an entrepreneur perceives, to the extent that he/she would find it profitable to enter Bihar to set up operations even if his origins were outside Bihar. This measure (we term it counterfactual) is categorical, the categories being "yes" (entrepreneur would do business in Bihar even if from outside Bihar), "no" (entrepreneur would not do business in Bihar if a native of the state) and "uncertain" (entrepreneur is uncertain about his/her choice). This measure captures CFT present in entrepreneurial identity arising from a location-specific factor.

Given the history of problematic governance in Bihar prior to 2006, we feel the second issue is very important as it reflects on the safety of investments, a primary driver of ease of doing business expectations and gains importance for deriving appropriate industrial policy implications. 


\section{Development of Empirically Testable Hypotheses}

There are two ways to understand outcomes in the food processing sector from a micro-agency perspective. Ceteris paribus the institutional and unobservables, outcomes can be observed from the functional efficiency of the enterprise as well as from an individualistic entrepreneurial ability perspective. The latter, though more of a socio-anthropocentric study of entrepreneurship, matters a lot when the industrial bases as well as institutions for industrialization are low and weakly developed as is the case for Bihar. The former approach, which can be understood from an efficiency analysis (in the sense of output per unit of input provided), is more along the lines of traditional economic analysis.

The other measure more reflective of entrepreneurial ability is experience of the entrepreneur, where experience is meant to capture exposure to all activity (such as trading) related to business prior and during the period of enterprise activity as revealed during the interview. This variable can take a value higher than the age of the unit given our definition of experience.

The importance of experience in enabling entrepreneurship is becoming increasingly clear in the literature, particularly trading experience such as Munshi (2010). Trading creates a human capital in the form of knowledge of supply chains as well as a clear understanding of the nature of the business as well as consumer mindsets apart from creating the necessary wealth for moving on to the next stage of business: entrepreneurship, where the trader becomes an independent operator thereby becoming the residual claimant of risk, which she/he could avoid through fixed payment trading contracts.

In our study, we test for both; whether prior experience correlates to entrepreneurial aspirations (which are also indicative of the wealth-creation potential of trading activity) as well as informational advantages of experience which should be reflected in risk perceptions. The former is more along the lines of existing literature, whereas the latter is our addition to understanding the genesis of entrepreneurship through the lens of perception of risk.

Both these aspects of entrepreneurial functioning (efficiency of operations and outlook of business risk) are likely to be a function of whether entry into business is due to self-interest or due to existing family concerns. Inheriting land and business operations reduces the burden of starting a new business. However, familial involvement through financial or managerial participation is indicative of informality of operations, without the involvement of management professionals hired from outside the family to incorporate best business practices into daily operations.

Interestingly, though 17 entrepreneurs note the latter as the reason for business entry, continuous engagement of family members in various aspects of enterprise operations have been mentioned by almost all the remaining 59 entrepreneurs. None of the units are listed on stock exchanges and a few began as limited liability partnerships (LLPs) ${ }^{5}$, with equity participation from various family members. Majority of these operations involve family members in

${ }^{5}$ Five units continue to be LLPs. 
managerial positions and the distinction between profits earned from the business and personal income is blurred and fungible ${ }^{6}$.

In terms of methodological approach towards understanding drivers of entrepreneurial perceptions, we abandon the efficiency-based approach such as Stochastic Frontier Approach (SFA) or Data Envelopment Analysis (DEA) in preference for a direct description of risk perceptions and their potential contributors. The primary reason for not adopting an SFA or a DEA technique for capturing efficiency at the level of the food processing sector level (encompassing the six selected sub-sectors) is that this methodology is not amenable to multiple sub-sectoral pooling of units. Efficiency drivers for rice milling (dependent on technology employed therein) vary significantly from that for cold storages. Hence, there is no meaningful way to capture the overall efficiency of units in food processing. If we restrict ourselves to the sub-sectoral level, either SFA or DEA will not be very robust as some sub-sectors have very few observations (such as four units for dairy).

Given our research objective, our testable hypotheses are:

H0. Entrepreneurial identity generated by domicile state of the entrepreneur (measured through a location-specific counterfactual) is reflected in her/his risk perception.

This test corroborates that our scale measure of risk perception (also captured through the two categories of risk code) captures the same concept as captured by the counterfactual. If we establish this hypothesis through our data, we can claim that CFT in entrepreneurial identity is captured through their perception of risk in industrial contexts similar to Bihar.

H1. Risk perception and CFT is not constant for different cohorts of entrepreneurs.

H1a. (Business Specific Linkage) Risk perception (and CFT) is a function of the specific sub-sector in which the entrepreneur operates.

H1b. (Resource Specific Linkage) Risk perception (and CFT) varies according to enterprise size, land holding and access to finance.

H1c. (Policy Linkage) Risk perception (and CFT) varies according to government subsidy.

H1d. (Attribute Specific Linkage) Risk perception (and CFT) varies according to father's occupation or entrepreneurial experience.

The purpose of this hypothesis is to reconcile the two contrasting results in the cognitive literature on entrepreneurship, one of which claims that entrepreneurs do not engage in significant counterfactual thinking as compared to a nonentrepreneur whereas the other claims significant CFT among entrepreneurs. We check for differential CFT among different types of entrepreneurs, where the segregated classes are based on either business-specific reason (sub-sectoral

${ }^{6}$ Informality in operations is evident as the accounting of books is done by the entrepreneur herself/himself as she/he is a Chartered Accountant (as was the case with at least three units). 
specificities of operations resulting in differential technological and business cycle risks), resource-specific conditions such as enterprise size, land and access to finance, policy conditionings measured by access to government subsidy or entrepreneurial attribute specific linkage such as gender, family influence (measured by father's occupation) and experience.

\section{Results and Discussion}

\section{Sample Description}

The distribution of units in our sample is shown in Table 1.

Table 1. Distribution of Various Units in Primary Survey for Food Processing in Bihar

\begin{tabular}{|l|c|}
\hline Enterprise Type & Number of units sampled \\
\hline Cattle/Poultry Feed (maize-based) & 9 \\
\hline Cold Storage & 15 \\
\hline Rice Mills & 19 \\
\hline Honey-based & 8 \\
\hline Dairy & 4 \\
\hline Others & 21 \\
\hline Total & 76 \\
\hline
\end{tabular}

Source: Author.

To capture functional diversity and explore efficiency of units, we include in our sample not only mature units across sub-sectors, but non-functional units (closed as well as yet-to-start-operations) in our sample. We also have a variation in terms of maturity (units less than one year old we term nascent and more than one year as mature). Not only does this help us avoid survival bias in our sample, it also helps us correlate outcomes with risk perception, which was our primary objective for conducting the survey. Of the total 76 units, the majority 61 are functional and mature units, whereas 8 units are nascent (less than a year old), 2 units are in a planning stage (production yet to begin) and 5 units are nonfunctional and in various stages of exit.

Note that none of these businesses are exporters and their marketing is limited to consumers within the state of Bihar.

\section{Variable Description}

Size of Enterprise: Note that around 60 per cent of the sample report an initial cost (including land, machinery and plant) less than 0.7 million USD in current prices (characterized as small units by the Ministry of Micro, Small \& Medium Enterprises, Government of India). The remaining 40 per cent of the sample have project sizes less than 7 million USD in current prices. Only two functional units (both in dairy processing) have a project size of 17 million USD in current prices. The pattern of many small and few large comes out 
through other measures as well, such as land size (majority with less than one acre of land and a minuscule with over 50 acres). While this comforts us that our sampling strategy (though non-random and conducted with the specific purpose of identifying networks of entrepreneurs) does reflect the pattern in secondary data, this is anything but the picture of a healthy industrial scenario.

Education and Age: Our data has significant variation built in for parameters such as age and education. The average age of the entrepreneur in our sample is 45.4 years, with a large age variation from 21 to 72 years. The lowest education qualification is a Class X (4 individuals) ranging right up to doctoral degrees ( 3 entrepreneurs) and professional qualifications such as Chartered Accountancy (1 observation) and MBA from universities in India and the UK (total 10).

Entrepreneur Origin: However, there is much lower variation for origin of the entrepreneur. We define an indigenous entrepreneur as one whose last three generations have been in Bihar. Sixty four of the 76 sample points are indigenous entrepreneurs. Being in the local conditions matter, as majority interviewed mentioned that they are doing business in Bihar because "they are from Bihar" and in fact, as our later observations show, display skepticism as to whether they would do business had they been outsiders.

Women Entrepreneurship: Similarly, we have very few women entrepreneurs (only eight women with relatively small projects (other than a wheat milling plant)). Low female entrepreneurship, despite special incentives in successive industrial policies of the state, is reflective of the overall low human capital outcomes (education, skilling, work force participation). For most of the women interviewed, their entrepreneurial income is seen as an additional input to total family income and not an essential component of financial buoyancy of their families. This possibly translates to lower risk perceptions among women in our sample, as they have an easier outside option.

Main Cost Component: The main cost component for the enterprises was the fixed cost of plant, machinery and civil works (for more than fifty per cent of the sample) followed by the running cost of electricity. Only six enterprises mentioned the fixed cost of land as the most important component of setting up business operations. While there is some sub-sectoral pattern in the cost component (cold storages mention electricity as the main source of expenditure, whereas some rice mills consider the variable cost of paddy input as the highest cost component), the pattern is to be understood with the age of the unit, as many of the older establishments have already amortized their fixed costs, and are more concerned about variable costs of operations.

Father's Occupation: Exposure to business activities through father's profession helps in forming attitude to business prospects and risks. In our sample, there is some variation regarding this, with 27 entrepreneurs reporting that their fathers were either in same/unrelated business or involved in trading activities and 16 others mentioning that their fathers were either farmers owning land or zamindars (landowners). The remaining 33 entrepreneurs report diverse professions for their fathers (ranging from professors to government employees to mukhiya) mostly in the service sector. It is interesting to note that though the 
majority of the sample mention self-interest as the reason for doing business, majority of the father's profession was unrelated to business.

Type and size of land: Related to the earlier variable is ownership of land or rather, the type of land on which the unit is established. Half the samples have put up their manufacturing on their own land, which they have leased to the unit. Among the remaining 38, the majority of 28 have leased land from the BIADA (Bihar Industrial Area Development Authority). Given the increasing circle rates due to pressure from the demand side, the latter option has become extremely expensive. According to some of the older establishments, setting up operations on BIADA land with current lease rates would make operations financially unviable.

Land size is a difficult variable, which reflects the problem of the extreme distribution of project sizes in the sample (as is the case with the population of firms in Bihar, as pointed out in the previous chapter). The mean size holding is 27.88 acres, which is small by industrial standards in India. However, the standard deviation of 199.04 is much larger than the mean and is resonant of the large variation in unit sizes.

Membership in Associations: Exactly half the samples do not have any membership with any of the business associations within the state, such as the Bihar Chamber of Commerce or the Bihar Industries Association. Nonetheless, they do have contacts with members of such associations, who referred them to us (due to our sampling strategy). Only six members have multiple memberships (these are old established units). As these associations, which have a representation with the government, are located in Patna, units in the distant districts do not find membership with these associations improving their lobbying power or information sources. Most of the consumption markets (for the small units) are concentrated in the local regions and are not even an all-Bihar presence; hence it is rational not to invest in these memberships.

Experience: We capture prior experience as traders before each entrepreneur in our sample. With 15 missing observations, the minimum and maximum years of experience is zero and forty-six respectively, with a mean of 13.26 years and a relatively large standard deviation of 10.79 years.

Marketing: Other than for cold storages, almost all units market their own products under their own brand names. Almost all cold storages in Bihar operate on a rental model, where the owner lets farmers store their produce in the cold storage against a rental. Most of these sell the final produce as a part of business policy; only when they are forced to when the farmer refuses to collect the stored product at the going rental due to price reductions in the market. Few exceptions are in Nalanda, where the cold storages store flowers which they sell to tourists and in Hajipur, where the owner sells unbranded apples in cartons to buyers in Delhi. However, in terms of using modern retail marketing channels such as online platforms, only two entrepreneurs mentioned that they are considering these options to diversify marketing risks.

Business Outlook (Strengths and Challenges): We asked the entrepreneurs to identify the top two factors that are the strengths and challenges for the subsector that they are functioning in. We asked this question in terms of overall macro variables which affect all units, and not their own business operations 
alone. This helps us capture what an individual entrepreneur perceives is the overall challenge as well as advantage of doing business in their line of activity. This variable helps us capture shared vision and goals at the subsectoral level among entrepreneurs.

Interestingly, there is no uniformity in business outlook in terms of challenges, even within our small sample. Among the important problems are: corruption and law and order, availability of land, inadequate infrastructure (either absent or very poor Industrial Area, identified by entrepreneurs in districts further away from Patna/Hajipur), inadequate information and policy thrust and finance.

However, in terms of sub-sectoral strengths, there was uniformity in responses: abundant raw material resources, large local demand (low competition other than for rice mills) and no labor trouble. It is difficult to create an index from the responses, particularly for challenges, as some of the responses are unique and not shared by any other respondent (for instance, declining productivity of fruit yields (litchi) due to inadequate research and development).

\section{Test of Hypotheses}

At the outset, note that three entrepreneurs are multi-plant and multi-sector (one of them has three separate units), which we count as individual responses for our analysis, as we ensured during our interviews that the responses be catered to for each unit separately. However, for the risk perception variables, there is a duplication of observations (as we find no variation in these responses across units for an individual entrepreneur). We also have some non-responses for the counterfactual variable, so that the valid no. of observations $(\mathrm{N})$ for our study is 71. While it is understandable that the counterfactual variable is slightly harder to mentalize, we have remarkably consistent answers, showing that our two measures are indicative of risk perceptions.

H0. Entrepreneurial identity generated by domicile state of the entrepreneur (measured through a location-specific counterfactual) is reflected in her/his risk perception.

In order to test this hypothesis, we check whether responses with a high direct risk perception (low scale measure as explained later) also answer in the negative ("no") for the counterfactual. Results are reported in Table 2.

Table 2. Risk Code * Location-Specific Counterfactual (CFT) Crosstabulation

\begin{tabular}{|l|c|c|c|c|}
\hline \multirow{2}{*}{ Risk Code } & \multicolumn{4}{|c|}{ Location-Specific CFT } \\
\cline { 2 - 5 } & Uncertain & No & Yes & Total \\
\hline Risk Code 1 (High Risk) & 6 & 23 & 5 & 34 \\
\hline Risk Code 2 (Low Risk) & 4 & 17 & 16 & 37 \\
\hline Total & 10 & 40 & 21 & 71 \\
\hline
\end{tabular}

Source: Author. 
Table 2 shows the cross-tabulations of the categorized risk code against the counterfactual. While the total number of responses for a high direct risk perception (34) is marginally lower than that for low risk perception (37), there is a clear correlation in the number of entrepreneurs who mention that they would never do business in Bihar if they were not indigenous to the state and entrepreneurs with a high perception of risk. Twenty three of the 34 high risk entrepreneurs answer a "no" for the counterfactual, which is around 68 per cent of the total high risk entrepreneurs. The percentage of low risk entrepreneurs who answer "no" for the counterfactual is 46 (17 out of 37 low risk responses). On the other hand, 43 per cent (16 of 37) of the high risk entrepreneurs answer "yes" for the counterfactual, whereas only 15 per cent of the low risk entrepreneurs (5 out of 34) give an affirmative response.

This is a clear indication of the direction of risk responses: higher perception of risk is correlated positively with a negative impression of doing business in Bihar (independent of input advantages) and vice versa.

Hence, we confirm our hypothesis H0. (that counterfactual thinking is reflected in risk perceptions).

H1a. (Business Specific Linkage) Risk perception (and CFT) is a function of the specific sub-sector in which the entrepreneur operates.

We find no direct evidence of any sub-sectoral pattern with risk perception. It is not the case that rice millers display a significantly high perception of risk than cold storage or other units. Hence, for the purpose of the risk assessment, we club all units together and present our central results for the rest of the analysis. This also shows that H1a. is not valid in our data: risk perception is not driven by business specific linkages defined by the specificities of nature of business.

H1b. (Resource Specific Linkage) Risk perception (and CFT) varies according to enterprise size, land holding and access to formal finance.

H1c. (Policy Linkage) Risk perception (and CFT) varies according to government subsidy.

In our data, neither loan size (access to formal finance) nor government subsidy show a statistically significant correlation with the risk perception (scale measure). Though size of land-holding (and hence size of the enterprise) is positively correlated with risk perception (scale measure), the Pearson correlation coefficient of 0.013 is not statistically significant. Therefore, we conclude that our data does not support H1b. or Hlc.

Hld. (Attribute Specific Linkage) Risk perception (and CFT) varies according to father's occupation or entrepreneurial experience.

We find experience matters for direct perception of risk. We reconvert to actual numbers (on the scale from 0 to five) for the direct risk perception measure, as experience is a continuous measure. We present in Table 3 results of the correlation between direct risk perception and experience. 
Table 3. Pearson Correlation Coefficient between Risk Perception and Experience

\begin{tabular}{|l|c|c|}
\hline & Risk Perception & Experience \\
\hline Risk Perception & 1.00 & \\
\hline Experience & $0.27^{*}$ & 1.00 \\
\hline$*$ indicates statistical significance at 0.05 level (2-tailed test) \\
\hline
\end{tabular}

Source: Author.

Experience is positively correlated with higher values of the risk perception scale measure, which translate to low risk perception and is along the lines of existing literature (Podoynitsyna, Bij \& Song (2012) and Munshi (2010)).

Investigating the manner in which experience matters for risk perceptions, we control for whether the entrepreneur belongs to a business family (and therefore perceptions of risk are inherited). We find that father's occupation is uncorrelated with risk perception code. Rather, as Table 4 shows, we find a positive correlation of the risk perception code with membership of business associations. The higher the number of memberships, lower is the perception of risk in Table 4, where percentages are mentioned in parentheses.

Table 4. Risk Code* Membership Crosstabulation

\begin{tabular}{|l|c|c|c|}
\hline $\begin{array}{l}\text { Association } \\
\text { Membership }\end{array}$ & $\begin{array}{c}\text { Risk Code 1 } \\
\text { (High Risk) [Per cent } \\
\text { of Total] }\end{array}$ & $\begin{array}{c}\text { Risk Code 2 } \\
\text { (Low Risk) [Per cent } \\
\text { of Total] }\end{array}$ & $\begin{array}{c}\text { Total [Per } \\
\text { cent] }\end{array}$ \\
\hline Zero & $21[0.55]$ & $17[0.45]$ & $38[100]$ \\
\hline One & $11[0.41]$ & $16[0.59]$ & $27[100]$ \\
\hline More than One & $2[0.33]$ & $4[0.67]$ & $6[100]$ \\
\hline
\end{tabular}

Source: Author.

Clearly, higher number of memberships in associations (which comes with associated membership fees) is exhibited by entrepreneurs who are established in business and who benefit from information exchange, networking with other members and lobby the government. Therefore, our data provides support for hypothesis H1d, which differentiates between family influence and business network's effect on perception of risk. The latter is significantly positively correlated with experience in our data, but not correlated with father's profession, underscoring the process of becoming an entrepreneur requires access to business networks and associations, which allow access to information and mitigate risk perception. Podoynitsyna, Bij \& Song (2012) find a similar result in the context of mixed emotions for entrepreneurship.

Clubbing hypotheses H1a., b., c. and d., we conclude that entrepreneurial risk perception varies according to experience in the following manner: novice entrepreneurs have a negative location-based CFT coupled with high perception of risk whereas those with more experience exhibit the opposite behavior. This leads us to confirm hypothesis $\mathrm{H} 1$ using our data:

H1. Risk perception and CFT is not constant for different cohorts of entrepreneurs. 
Test of Representativeness of Sample: Evidence of Missing Middle Enterprise Size

Tying up with our discussion in the introduction, we mentioned the absence of a "middle size" of enterprises in Bihar, the reason being the prevalence of poor law and order conditions in the state prior to 2006 (Chakrabarti 2013). We test for this in the population of all enterprises in Bihar for 2014-15, just prior to our survey in 2016. Using secondary data from the Registrar of Companies, Patna (which has the incorporation details as well as details of authorized and paid-up capital), we find from Table 5 that the coefficient of variation of financials of all registered units exhibit very high variance relative to the mean.

Table 5. Coefficient of Variation for Financials in Selected Sectors for 2014-15

\begin{tabular}{|l|c|c|}
\hline \multirow{2}{*}{ Sub-sectors in Food Processing } & \multicolumn{2}{|c|}{ Coefficient of Variation } \\
\cline { 2 - 3 } & Authorized Capital & Paid-up Capital \\
\hline Dairy & 2.82 & 4.35 \\
\hline Cold Storage & 0.99 & 0.91 \\
\hline Rice Mills & 2.04 & 2.82 \\
\hline Animal Feeds & 1.27 & 1.49 \\
\hline
\end{tabular}

Source: Authors' own calculations using data from Registrar of Companies, Patna, Bihar.

The values for coefficient of variation (standard deviation normalized by the mean) are either very close to one (only for cold storage) or greater than one (for all other sub-sectors). Noting that the values of authorized and paid-up capital are in fact strictly positive, this amount of variation in the data must arise from an extreme size distribution with many small and some large firms with a missing middle size. This non-normality in the data is reflected in our sample. Given this variability in projects by size in our sample, we show that our sample is representative of the population.

\section{Policy Recommendations}

From a policy perspective, what is most interesting is that we could not establish any relationship (be it at the level of a correlation analysis or a causal analysis) between government subsidy available to the unit or the functional status of the unit or its marketing status and perception of risk. Nor were variables related to access to finance (such as loan access, rates of interest, working capital etc.) which could significantly explain perception of risk. We stress that we measure perception of risk in our study, and do not investigate constraints to doing business. Access to finance is a well-known constraint in the functioning of a business, but the extent to which it affects perception of risk is another matter altogether.

The denouement of the nascent industrial scenario in Bihar (post-2006) is beholden to its troubled past, with mis-governance up to 2000 (Mukherji and Mukherji 2012), which gave rise to the local kidnapping industry posing ransom threats to businessmen in the state leading up to the bifurcation of the state in 2000 (where south Bihar with all its mineral resources and heavy mining-based 
industries was lost to the newly carved state of Jharkhand). The post-2000 Bihar scenario presents a sharp decline up to 2006, in terms of all macro-indicators of state performance. The interesting turnaround of the state starts with the new government, which ensured a return to law and order (putting criminals behind bars) in the state. The second term of the same government (2011 onward) has shown a similar but a somewhat reduced pace of reforms in the state. The jump in business confidence is seen in the increase in registered manufacturing year-onyear.

It is an interesting observation for us to find that some existing entrepreneurs (particularly in rice milling) are considering Assam as an alternative state for expansion of business interests and not Bihar. In this context, the second and more nebulous variable which needs to be addressed after law and order can be termed overall ease of doing business in Bihar. An existing World Bank Group report (2015) ranks Bihar a modest 21 among 32 states (Gujarat is the leading state with Jharkhand at a surprising 3rd rank, Assam with a much lower rank of 22 and West Bengal with an intermediate 11th rank). This study uses eight parameters (setting up a business, allotment of land and obtaining construction permit, complying with environmental procedures, complying with labor regulations, infrastructurerelated utilities, registering and complying with tax procedures, carrying out inspections and enforcement of contracts) to create the ranking among states. Our initial interaction with entrepreneurs reveals a picture that is consonance with this ranking, which should be much enhanced in the near future if Bihar hopes to catch up with other states in terms of industrial achievements.

For our sample with the underlying bimodal distribution, with many small units and some very large units, we do not find that access to finance explaining business risk perception significantly. Access to finance does not matter for the large units, but it does matter crucially for the small units, which on the overall cancel out in the entire sample. The same logic applies for government subsidies. In sum, the only variables which showed any systematic patterns had to do with two entrepreneurial characteristics (experience and information access (proxied by membership of associations)). For Bihar, with the presence of many small and unprofessionally managed units coexisting with some large established enterprises, the nitpicking with respect to financial incentives through policy (subsidies and incentive structures) is unlikely to yield productive outcomes. Development of strong business networks and entrepreneurial coaching and exposure to the supply chain are potential directions for industrial policy to focus on rather than keeping the focus exclusively on pecuniary incentives.

\section{Conclusions}

Entrepreneurial expectations are not formed in a vacuum. It takes into account the local conditions and projects forward. Borrowing from explanations provided in Chakrabarti (2013), Mukherji and Mukherji (2012) and responses from entrepreneurs, we conjecture that the absence of a middle size is because these firm sizes were the most easy and lucrative targets for the kidnapping industry 
prior to 2006. The small firms and establishments in the informal sector are not profitable enough for demands of ransom, and large industries can purchase their protection from criminals. It is the middle size that suffers from this problem of threats of the private kidnapping industry.

In this paper, we measure the extent of the "entrepreneurial regret" in not being able to expand in the perception of risk of doing business by the entrepreneur by investigating the extent to which "being in Bihar" matters. This investigation adds to the relatively nascent literature on forced entrepreneurship: that doing business is not always about the natural drive of the human spirit to discover opportunities and convert them to profitable ventures, as the standard literature on identity in entrepreneurship would have us believe. To some extent, this is a comment about how "non-entrepreneurial" mind-sets cope in a business scenario: essentially, the story of the reluctant entrepreneur.

\section{Acknowledgements}

The author would like to thank the IGC, LSE, London for financing this study and participants in the $13^{\text {th }}$ Annual International Symposium on Economic Theory, Policy and Applications, 2-5 July 2018, Athens, Greece for useful comments that enriched the final paper. Additional comments from Prof. Anjan Mukherji and Dr. Maitreesh Ghatak (LSE) on the final Report of the project are gratefully acknowledged. Dr. Barna Ganguli's help in conducting the survey in Bihar, alongside research assistance from Amresh Kumar and Prabhat Kumar is worthy of mention. Asian Development Research Institute (ADRI, Patna) helped me in many arrangements for the study and the author thanks Dr. Shaibal Gupta, Dr. Sunita Lall and Dr. Prabhat Ghosh for their contribution for aiding the completion of the project.

\section{References}

Baron RA (2000) Psychological perspectives on entrepreneurship: Cognitive and social factors in entrepreneurs' success. Current directions in psychological science 9(1): 15-18.

Baron RA (2008) The role of affect in the entrepreneurial process. Academy of management Review 33(2): 328-340.

Baron RA, Markman GD (1999) Cognitive mechanisms: Potential differences between entrepreneurs and non-entrepreneurs. Frontiers of entrepreneurship research, 123137.

Baum JR, Locke EA (2004) The relationship of entrepreneurial traits, skill, and motivation to subsequent venture growth. Journal of applied psychology 89(4): 587.

Baum JR, Locke EA, Smith KG (2001) A multidimensional model of venture growth. Academy of management journal 44(2): 292-303.

Baumol WJ (1993) Formal entrepreneurship theory in economics: Existence and bounds. Journal of business venturing, 8(3): 197-210.

Burke PJ (2004) Identities, Events and Moods. In Turner JH (ed). Theory and Research on Human Emotions (21): 25-49. New York: Elsevier Ltd. 
Burke PJ (1980) The Self: Measurement Requirements from an Interactionist Perspective. Social Psychology Quarterly 43(1): 18-29.

Burke PJ (1991a) Identity Processes and Social Stress. American Sociological Review 56(6): 836-849.

Burke PJ (1991b) Attitudes, Behavior and the Self. In Howard JA, Callero PL (eds). The Self-Society Dynamic: Cognition, Emotion and Action, 189-208. New York: Cambridge University Press.

Burke PJ, Stets JE (2009) Identity theory. Oxford University Press.

Cardon MS, Wincent J, Singh J, Drnovsek M (2009) The nature and experience of entrepreneurial passion. Academy of management Review 34(3): 511-532.

Cast AD (2004) Well-being and the transition to parenthood: An identity theory approach. Sociological Perspectives 47(1): 55-78.

Chakrabarti R (2013) Bihar Breakthrough: The Turnaround of a Beleaguered State. Rupa Publications India Pvt. Ltd.

Chen XP, Yao X, Kotha S (2009) Entrepreneur passion and preparedness in business plan presentations: a persuasion analysis of venture capitalists' funding decisions. Academy of Management journal 52(1): 199-214.

Dawson C, Henley A (2013) Over-optimism and entry and exit from self-employment. International Small Business Journal 31(8): 938-954.

Falck O, Heblich S, Luedemann E (2012) Identity and entrepreneurship: do school peers shape entrepreneurial intentions? Small Business Economics 39(1): 39-59.

Gaglio CM (2004) The role of mental simulations and counterfactual thinking in the opportunity identification process. Entrepreneurship Theory and Practice, 28(6): 533-552.

Gaglio CM, Katz JA (2001) The psychological basis of opportunity identification: Entrepreneurial alertness. Small business economics 16(2): 95-111.

Gartner WB (1988) "Who is an entrepreneur?" is the wrong question. American journal of small business, 12(4): 11-32.

Gartner WB, Shaver KG, Gatewood E, Katz JA (1994) Finding the entrepreneur in entrepreneurship.

Gecas V (1982) The self-concept. Annual review of sociology 8(1): 1-33.

Gimeno J, Folta TB, Cooper AC, Woo CY (1997) Survival of the fittest? Entrepreneurial human capital and the persistence of underperforming firms. Administrative science quarterly, 750-783.

Haynie JM, Shepherd DA, McMullen JS (2009) An opportunity for me? The role of resources in opportunity evaluation decisions. Journal of Management studies 46(3): 337-361.

Hmieleski KM, Corbett AC (2008) The contrasting interaction effects of improvisational behavior with entrepreneurial self-efficacy on new venture performance and entrepreneur work satisfaction. Journal of business venturing 23(4): 482-496.

Kahneman D, Tversky A (1973) On the psychology of prediction. Psychological review 80(4): 237.

Kihlstrom RE, Laffont JJ (1979) A general equilibrium entrepreneurial theory of firm formation based on risk aversion. Journal of political economy 87(4): 719-748.

Markman GD, Baron RA, Balkin DB (2005) Are perseverance and self-efficacy costless? Assessing entrepreneurs' regretful thinking. Journal of Organizational Behavior: The International Journal of Industrial, Occupational and Organizational Psychology and Behavior 26(1): 1-19.

McCall GJ, Simmons JL (1978) Identities and interactions: An examination of human associations in everyday life (Rev. ed.). New York, 
McClelland DC (1965) N achievement and entrepreneurship: A longitudinal study. Journal of Personality and Social Psychology 1(4): 389.

McGrath RG, MacMillan IC (2000) The entrepreneurial mindset: Strategies for continuously creating opportunity in an age of uncertainty (Vol. 284).

Mukherji A, Mukherji A (2012) Bihar: What Went Wrong? And What Changed? NIPFP Working Paper No. 2012-107.

Munshi K (2010) The Birth of a Business Community: Historical Disadvantage and Contemporary Mobility in India. Review of Economic Studies, forthcoming.

Murnieks CY, Mosakowski EM (2007) Who Am I? Looking Inside the "Entrepreneurial Identity", Frontiers of Entrepreneurship Research 27 (5): Article 5. Retrieved from https://bit.ly/2PLMtOy.

Murnieks CY, Mosakowski E, Cardon MS (2014) Pathways of passion: Identity centrality, passion, and behavior among entrepreneurs. Journal of Management 40(6): 15831606.

Newman M (2018) Networks. Oxford university press. Second edition.

Noy C (2008) Sampling knowledge: the hermeneutics of snowball sampling in qualitative research, International Journal of Social Research Methodology 11 (4): 327-344

Podoynitsyna K, Van der Bij H, Song M (2012) The role of mixed emotions in the risk perception of novice and serial entrepreneurs. Entrepreneurship theory and practice 36(1): $115-140$.

Russo JE, Schoemaker PJ (1992) Managing overconfidence. Sloan management review 33(2): 7-17.

Sánchez JC, Carballo T, Gutiérrez A (2011) The entrepreneur from a cognitive approach. Psicothema 23(3): 433-438.

Schumpeter JA (1934) Change and the Entrepreneur. Essays of JA Schumpeter.

Shane S, Venkataraman S 2000 The promise of entrepreneurship as a field of research. Academy of management review 25(1): 217-226.

Sitkin SB, Pablo AL (1992) Reconceptualizing the determinants of risk behavior. Academy of management review 17(1): 9-38.

Sitkin SB, Weingart LR (1995) Determinants of risky decision-making behavior: A test of the mediating role of risk perceptions and propensity. Academy of management Journal 38(6): 1573-1592.

Stryker S, Burke PJ (2000) The past, present, and future of an identity theory. Social psychology quarterly, 284-297.

Wadeson N (2006) Cognitive aspects of entrepreneurship: decision-making and attitudes to risk. In The Oxford handbook of entrepreneurship.

Zhao H, Seibert SE, Hills GE (2005) The mediating role of self-efficacy in the development of entrepreneurial intentions. Journal of applied psychology 90(6):1265. 